\title{
The Effect of a Method to Enhance Self-Acceptance and Acceptance of Others through Collaborative Team's Role Recognition
}

\author{
Mayu Akaki *, Nobuyuki Kobayashi ${ }^{\dagger}$, \\ Seiko Shirasaka *, Makoto Ioki *
}

\begin{abstract}
It is necessary to enhance team performance by unleashing each member's abilities in order to achieve the goal in business collaboration situations. However, it is a problem when each member does not recognize its strengths to demonstrate and the team performance is not enhanced. The purpose of this study is to enhance team performance by making each member able to recognize and unleash its abilities. We propose a method that aims to make individuals understand their situations through an advice sheet from the third person outside the team. In particular, the advice writer gives a description of advice to the team and individuals, based on the pre-survey that individuals answered their role recognition of themselves and team members. The method is evaluated by the change in self-acceptance and acceptance of others. The result indicates that the proposed method improves the acceptance level of examinees with low self-acceptance and acceptance of others at the pre-survey, who are the target of this study. The analysis of the free descriptions identifies that acceptance of others follows after self-acceptance. We also indicate the effects of the advice sheet to change self-acceptance and acceptance of others through the analysis of the interviews with the five examinees.
\end{abstract}

Keywords: acceptance of others, role recognition, self-acceptance, team collaboration

\section{Introduction}

It is a problem when each member does not recognize its strength to demonstrate and the team performance is not enhanced. According to Kobayashi et al. [1], the feasibility to accomplish the companies' vision improves through making the decision to execute by understanding the situation of the organization at first and sharing the recognition inside the organization secondly. This study deals with the organization as individuals and the whole company as a team of 3-6 people, which is the minimal size of a group of people with collaborations. The purpose of this study is

\footnotetext{
* Graduate School of System Design and Management, Keio University, Kanagawa, Japan

$\dagger$ The System Design and Management Research Institute of Graduate School of System Design and Management, Keio University, Kanagawa, Japan
} 
to enhance team performance by making each member able to recognize and unleash its abilities. We propose a method that aims to make individuals understand their situations through an advice sheet from the third person outside the team. In particular, the advice writer gives a description of advice to the team and individuals, based on a pre-survey that individual members answered their role recognition of themselves and team members. In terms of the process of role recognition, the advice sheet is designed based on the previous studies [2] [3], which indicate that acceptance of others is possible after self-acceptance and acceptance from others which raises one's selfacceptance.

The advice sheet was sent to eleven professionals and professional students of a graduate school (A K). The proposed method is evaluated by the changes in self-acceptance and acceptance of others. Since the changes indicate the rise of individuals' role recognition leading to enhance team performance level. The result indicates that the examinees with low self-acceptance and acceptance of others improved. In addition, the analysis of the free descriptions identified that it starts from the understanding of its character and role recognition of themselves (self-acceptance), followed by acquiring the mindset to utilize the strengths of team members (acceptance of others). We attempt to indicate the effects of the advice sheet to increase self-acceptance and acceptance of others and decrease the acceptance of others through the analysis of the interviews to five examinees, according to the changes that occurred to them by the proposed method. "Increase of self-acceptance" occurs by giving individuals a recognition of their strengths or roles they can take in the team, which leads to the motivation to change action during the team activities. "Decrease of acceptance of others" sounds seemingly negative, however, it affects the individuals to notice new aspects of the team members by mitigating the overestimation that they understand the team members' characters enough. "Increase of acceptance of others" occurs by reflecting the strengths of the team members, which leads to the mindset to utilize the strengths of each team member.

Section 2 summarizes previous studies. Section 3 describes the method proposed in this study. Section 4 describes the evaluation method used in this study. Section 5 shows and discusses the evaluation results using the method described in Section 4. Section 6 shows the discussion and Section 7 shows the limitation of this study. Section 8 concludes with future research directions.

\section{Literature Review}

(1) Team role

Belbin [4] classified the team role to eight types for the management team. He mentions that "the effectiveness of a team will be promoted by the extent to which members correctly recognize and adjust themselves to the relative strengths within the team, both in expertise and ability to engage in specific team roles". This study is based on his result that high role recognition leads to the enhancement of team performance. However, instead of classification of role types as Belbin [4], we indicate axis. That is because we deal with the collaborations in a flat relationship team aiming to make all the team members possible to contribute to improving the team performance spontaneously, instead of a subordinate-superior relationship or hierarchical relationship. 
(2) Self-acceptance and acceptance of others

The previous studies about self-acceptance and acceptance of others indicate that self-acceptance is a condition for the acceptance of others. Tanaka [5] indicates that leader identity also develops from self-concept to concept based on the relationship among others.

\section{(3) Effectiveness of the advice}

According to Takanashi's "conscious mind matrix of knowledge" [6], one's attitude toward learning from the "unknown information" changes, whether the individual "wants to know" or "does not want to know". From the information one "wants to know", individual "wants to learn" when one does not have an opportunity, or "has learned" when one had an opportunity. Also, in previous studies about the effectiveness of advice, Ricardo et al. [7] indicate that "the proportion of active adolescents, as well as, the duration, frequency, and intensity of leisure time exercise and/or sports are increased by physician advice". Angele et al. [8] indicate that "individuals who actively solicit advice ultimately improve performance".

This study aims to enhance team performance in business collaborations by utilizing the diverse team members' strong points with each other, not by enhancing the management system. However, the previous studies focus on the management teams. In addition, in order to utilize all the members' strengths, we combine self-acceptance and acceptance of others to promote the role recognition in the team. According to the previous studies, we adopt the advice sheet since the advice is effective to promote actions.

Therefore, the novelty of this study lies in proposing the advice sheet to improve the role recognition in flat relationship teams by combining self-acceptance and acceptance of others. Additionally, we indicate the effects of the advice sheet to self-acceptance and acceptance of others through the analysis of the interviews with five examinees, according to the changes occurred to them by receiving the advice sheet.

\section{Proposed Method}

The advice sheet is written by the advice writer outside the team in three steps in Figure 1 and is sent to each examinee. Examinees answer the survey before and after receiving the advice sheet so that we can evaluate the changes in self-acceptance and acceptance of others. Figure 1 shows the whole process to write and quantitatively evaluate the proposed method. As STEP 1, the examinees answer a pre-survey on their role recognition and stage of self-acceptance and acceptance of others. The advice writer acquires the information necessary to write the advice sheet from the pre-survey result. As STEP 2, the advice writer describes the advice to the team on assumed role sharing and the key person of the team. The advice writer describes the team advice before individuals in order to write specific advice to individuals in STEP 3 based on the overview of the team applying the advice which they described in STEP 2. Post-survey on self-acceptance and acceptance of others is conducted one week after the examines received the advice sheet. This is because we consider that the changes would not occur immediately after they receive the advice sheet but gradually changes as they work on projects figuring out how they utilize the advice in real team collaboration situations. 


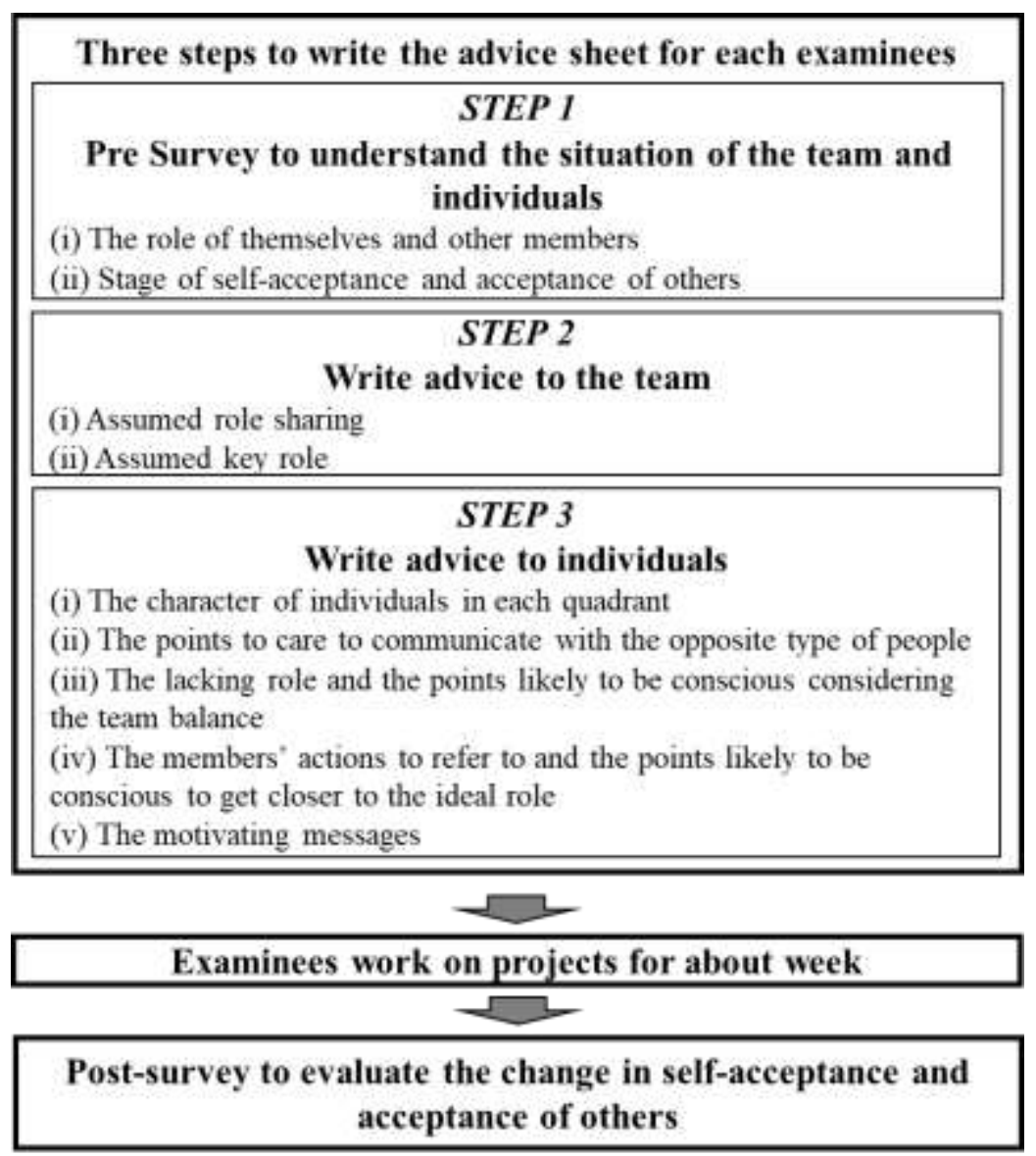

Figure 1: The process to evaluate the proposed method.

(1) (3) shows the details of each step to write the advice sheet.

\section{(1) STEP1: Pre-survey to understand the situation of the team and individuals}

We send out the pre-survey to the individuals to ask "(i) The role of themselves and other members" and "(ii) Stage of self-acceptance and acceptance of others". We asked 2 points of the role in the team, which are necessary to create outputs as a team. Particular questions are as Table 1.

- Divergent / Convergent: In which situation does the member show its strong points?

- Emotional / Logical: Which way of thinking does the member base on to make decisions?

Saito [9] defined creative thinking as the integration of divergent \& convergent thinking and experiential \& logical thinking. "Divergent" and "Convergent" can be measured by CAS (Creative Attitude Scale) [9]. Guilford [10] defines that divergent and convergent thinking is necessary for creativity. "Logical" and "Emotional" can be measured by IPSI (Information-Processing Style Inventory) [11], as "Rational" \& "Experiential". The items measure the logical understanding as "Rational" engagement items, and emotional expressivity in "Experiential" engagement items according to Pacini and Epstein [12]. Since this study aims to develop the method, instead of measuring the way of thinking, we did not use the scales but simply showed the definition and asked which type they are closer to as Table 1. 
Table 1: Pre-survey items asking role recognition.

Question: Please select your / each member's role in your team.

\section{- Divergent / Convergent}

A. Give new perspectives or ideas to the team.

B. Consolidate the opinions of the team to narrow down to the best idea. / Rather A than B / Rather B than A

\section{- Emotional / Logical}

A. Utilize one's emotions and make decisions by intuition.

B. Organize and structure the information and make decisions logically. / Rather A than B / Rather B than A

The advice writer visualizes the role recognition in 2-axis in the advice sheet as Figure 2. To the individuals whose all team members have answered the pre-survey, the advice writer indicates the difference among other team members. They can objectively understand the differences among the recognition of role sharing inside the team. In this study, we did not prepare items to ask whether the individuals or team members are multi-roller. That is because we can indicate that the individuals are multi-roller by taking the survey several times and finding out that they change their roles according to the team situations.

In designing the proposed method, we considered that the good balance of the roles in the team leads to good performance when all the members have acceptance of others. The reasons are that; only convergent [13] does not create new ideas, only divergent [13] does not refine or narrow down to the best idea, only logical thinking [14][15] does not generate empathy, and only emotional intelligence [16] does not explain things logically to convince others. However, when the level of acceptance of others in the team is not high enough, as Belbin [4] indicates that "the person in the Chair" is important to make winning teams, the stronger convergent direction is more likely to attain to the answer, but the idea may not be innovative.

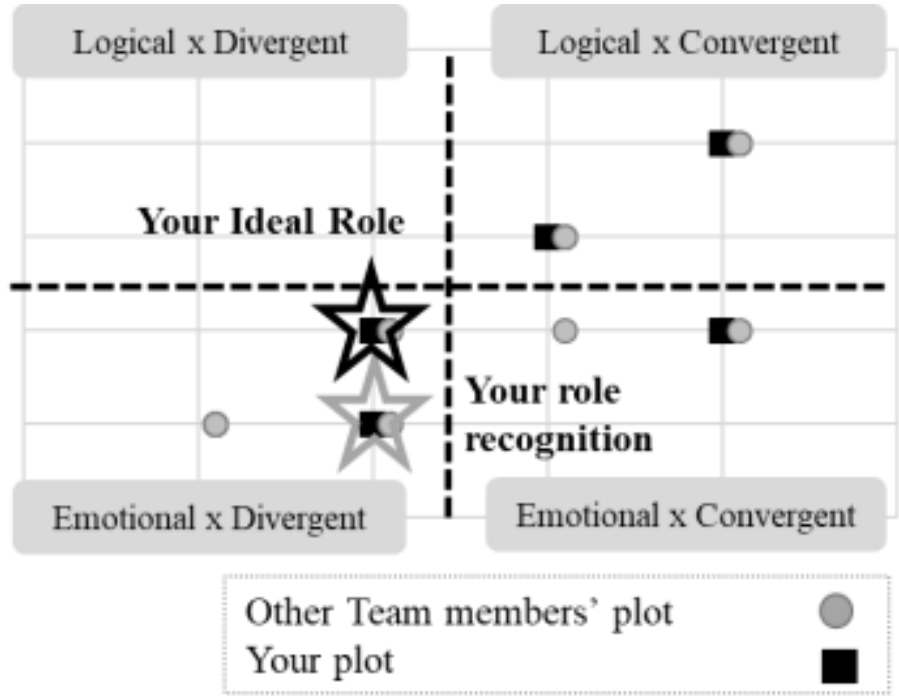

Figure 2: Example of 2 axes of role recognition of the team. 
Secondly, we ask the level of self-acceptance and acceptance of others by the items in Table 2. The advice writer adds one message to the individuals who have low self-acceptance and acceptance of others. It is because the previous studies [2][3] indicate that the acceptance from others raise one's self-acceptance. We aim to enhance positive self-acceptance through the advice.

Table 2: Pre-survey items asking self-acceptance and acceptance of others.

\section{Question: Please select the answer which is the closest to your situation}

\section{- The actions recognizing your role in the team}

1. Do not recognize your strengths and cannot act spontaneously

2. Take actions flexibly according to the requests of other members to fill in the open role in the team

3. Recognize your role, which is not your strong point, and take actions spontaneously

4. Recognize your strength and take actions spontaneously

5. Set your role according to your goal and take actions spontaneously

- The actions recognizing other members strengths in the team

1. Do not recognize other team members' strengths

2. Recognize other members' strengths but not taking actions according to them

3. Recognize some of the team members' strengths and take actions

4. Recognize all the team members' strengths and take actions

\section{(2) STEP 2: Write advice to the team}

Advice to the team is written about "(i) Assumed role sharing" and "(ii) Assumed key role" based on STEP 1 "(i) The role of themselves and other members".

"(i) Assumed role sharing" is written by the advice writer through the analysis of the situation from three points in Table 3. Pattern 1 and Pattern 3 is written to balance the way of thinking and situation to show their strong points and to reduce conflicts. Pattern 2 is written to utilize the members' way of thinking and strengths effectively.

“(ii) Assumed key role" is assumed from "(i) Assumed role sharing”. It is selected from the 3 patterns in Table 4.

Table 3: Three points to analyze the situation.

\begin{tabular}{|c|l|}
\hline 1 & There is at least one member in each quadrant: The team is balanced. \\
\hline 2 & $\begin{array}{l}\text { Many members' roles are close to the center: There are many members who have a sense } \\
\text { of balance. }\end{array}$ \\
\hline 3 & Many members' roles are in one particular quadrant: Write advice to balance the team. \\
\hline
\end{tabular}

Table 4: Three patterns of the Key Role

\begin{tabular}{|l|l|}
\hline 1 & A logical/emotional member, when many members are emotional/logical. \\
\hline 2 & $\begin{array}{l}\text { The member who has a specific situation to show its strong point, when many members" } \\
\text { roles are close to the center. }\end{array}$ \\
\hline 3 & $\begin{array}{l}\text { The member close to the center, when many members are "combination of emotional and } \\
\text { divergent" and "combination of logical and convergent". }\end{array}$ \\
\hline
\end{tabular}




\section{(3) STEP3: Write advice to individuals}

Advice to individuals is written by the advice writer from five points in Figure 1, based on STEP 1 and STEP 2. (i), (iii), and (v) are written to all the individuals. (ii) and (iv) are selectively written according to the situation. In order to enhance their self-acceptance by playing their ideal role, (iv) is written to the individuals whose ideal roles and current roles are different.

Like the "(i) Character of the individuals in each quadrant", the advice writer has written the five types of characters as Table 5. This study defines the combination of emotional/logical and divergent/convergent, for instance, as "Emotional x Divergent".

As "(ii) The points to care to communicate with the opposite type of people", the advice is written to "Emotional x Divergent" and "Logical x Convergent" who have the opposite character. The example advice is as Table 6 .

Table 5. Advice example of five types of characters.

“Emotional $x$ Divergent": You are sensitive and can think of the ideas outside the box. It depends on you how unique the team's idea would be.

"Logical x Divergent": You are a key person to balance the team. It is because you can

2 explain the ideas logically and control the discussion at the divergent situations when usually "emotional x divergent" and "logical x convergent" take the lead.

3 "Logical $\boldsymbol{x}$ Convergent": Your strong point is that you can logically convince others and organize the discussions to narrow down to the best idea.

"Emotional $\boldsymbol{x}$ Convergent": Your strong point is that you can make decisions based on

4 your experiences and intuitions. The team members will learn from your verbalized senses.

5 Balanced type close to the center: You have a sense of balance to keep a good balance in the team.

Table 6: Advice Example to the opposite type of character.

\begin{tabular}{|l|l|}
\hline 1 & $\begin{array}{l}\text { "Emotional } \boldsymbol{x} \text { Divergent": You can make efforts to communicate simply and logically to } \\
\text { understand each other with the "Logical x Convergent" type member, which has an oppo- } \\
\text { site character with you. }\end{array}$ \\
\hline 2 & $\begin{array}{l}\text { "Logical } \boldsymbol{x} \text { Convergent": You can find out new ways of thinking and a new role to take } \\
\text { in teams by working on a project with the opposite type "Emotional x Convergent" mem- } \\
\text { bers. }\end{array}$ \\
\hline
\end{tabular}

Especially when taking pre-survey to all the team members, the advice writer indicates that there are roles which the individuals are not aware of, and the difference of recognition with other members. As "(iii) The lacking role and the points likely to be conscious considering the team balance", the advice is written to encourage individuals to understand themselves and other members' strong points. For instance, the advice to examinee $\mathrm{C}$ is as below.

"There might be an "Emotional $x$ Divergent" type member in your team besides you. If you find a member close to your character, you can make efforts to build a relationship to utilize the emotion of each other. Other members might be not logical as much as you are thinking." 
We asked "The ideal role that is different from your current role. (don't need to answer if your current role is the ideal one.)" at the pre-survey. As "(iv) The members' actions to refer to and the points likely to be conscious to get closer to the ideal role", the advice is given to the individuals whose ideal and current roles are different. Table 7 shows examples of advice.

Table 7: Example of advice to individuals whose ideal and current roles are different.

1 Aiming to be logical: By observing and communicating with the "Logical x Divergent" type member in your team, you might get a hint to lead the discussion logically.

2 Aiming to be emotional: When the team is in a divergent situation, you can provide ideas following your emotion to become closer to your ideal role.

Unleash abilities at divergent situations: At divergent situations, you can consciously 3 share the inputs you have with your team and summarize the discussions simply, not just explaining logically.

In addition, as "(v) The motivating message", the advice is written to give excitement and special feelings to the individuals in order to motivate them and to make the advice more acceptable. That is because, if this advice applies to the "does not want to know" information in "unknown information", the team members will not "learn" from them, even though we give "opportunities" [6]. The advice sheet's structure is as in Figure 3.

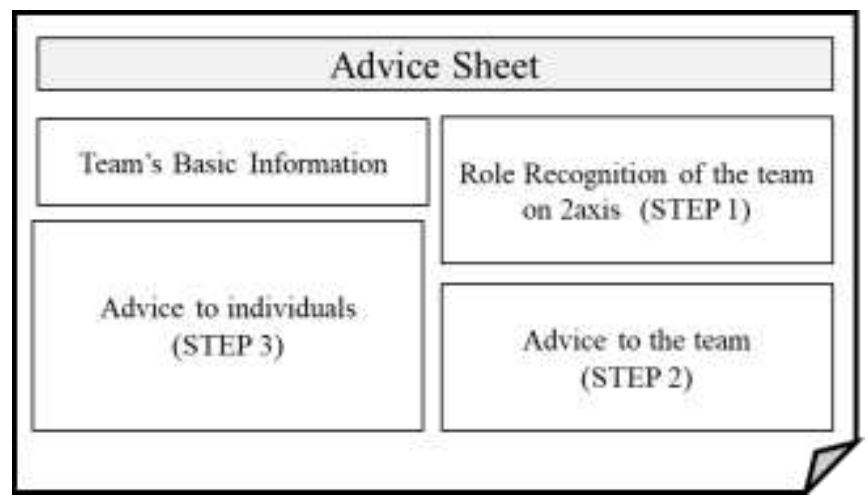

Figure 3: Advice Sheet structure.

\section{Evaluation Method}

The examinees are eleven professionals and professional students of a graduate school working on projects as teams of 3 6 people (A K). The way and procedure of evaluation are in Figure 4. 

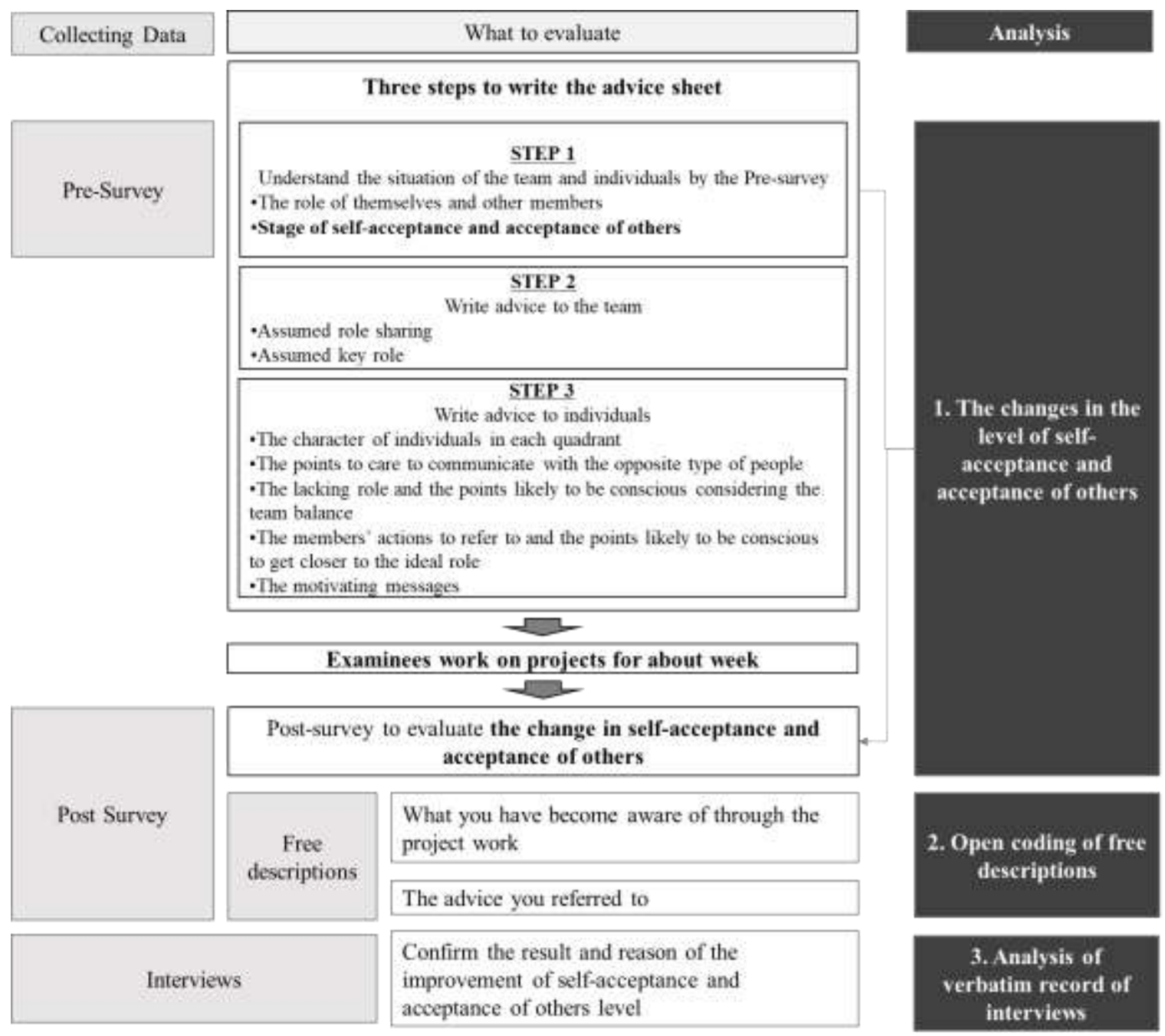

3. Analysis of

verbatim record of interviews

Figure 4: The way and procedure of evaluation.

We evaluated the level of self-acceptance and acceptance of others before and after sending the advice sheet as we mentioned in Figure 1. We repeated the process from "pre-survey" to "postsurvey" twice. From now on, "Pre" stands for pre-survey, "Post-1" stands for the post-survey for the first round, "Post-2" stands for the post-survey for the second round.

In addition to the quantitative analysis comparing the stage of self-acceptance and acceptance of others between pre- and post-survey, we conducted qualitative analyses by analyzing the free descriptions and interview results. Qualitative analyses support the result of quantitative analysis by suggesting how and why the changes occurred. In this study, we focused on subjective changes occurred to the examinees through the self-reported changes to evaluate the effect of the advice sheet. However, it is possible to objectively identify the changes that occurred to each individual by conducting mutual evaluation among team members.

We analyzed the free descriptions by "Open coding". The steps to implement open coding are described below. [17] 
Step 1: View the free descriptions on the post-survey and pick up the descriptions related to selfacceptance and acceptance of others. Set the viewpoint for Affinity Diagram grouping (Step 2). It was set in this study as "improvement of self-acceptance and acceptance of others using the proposed method," in order to show for what purpose the proposed method is useful.

Step 2: Look for, from the aforementioned viewpoint, the descriptions for the method that seems to be related, and sort them into groups.

Step 3: Write titles for each group that summarizes the essence of the group, at a slightly higher level of abstraction (called "Open coding results" in this study).

This study ensured the validity of the analysis by having one researcher skilled in qualitative research methods to review the analysis results. [18]

In order to confirm the changes in self-acceptance and acceptance of others, we conducted a 3060 minutes long interview with every five examinees in Table 8.

Table 8: The examinees being interviewed.

\begin{tabular}{|c|c|c|c|c|}
\hline \multirow{2}{*}{} & \multicolumn{2}{|c|}{ Changes in self-acceptance } & \multicolumn{2}{c|}{ Changes in acceptance of others } \\
\cline { 2 - 5 } & Post 1 & Post 2 & Post 1 & Post 2 \\
\hline B & +1 & +1 & +2 & +2 \\
\hline C & 0 & 0 & -1 & -1 \\
\hline E & 0 & +1 & -1 & -1 \\
\hline G & 0 & 0 & +4 & +3 \\
\hline H & +1 & +2 & 0 & -1 \\
\hline
\end{tabular}

\section{Evaluation Result}

We compare the results of the pre-survey (Pre) answered before sending the advice sheet and the first round's post-survey (Post-1), as well as the second round's post-survey (Post-2). According to Kawagishi [2], acceptance is defined as "accepting oneself and others' personality as it is and could be measured by the positive evaluation". Therefore, as for the level of acceptance, we asked: "the recognition and actions based on the strength" of individuals or other members.

Table 9 shows the changes in self-acceptance. Examinee B, F, and H's self-acceptance rose and examinee $\mathrm{J}$ and $\mathrm{K}$ decreased in Post-1. Since some examinees' result decreased, the average of the number decreased compared to the Pre. In Post-2, the results of the examinees B, E, and $\mathrm{H}$ improved, and none of the examinees decreased. As a result, the average number of Post- $2 \mathrm{im}-$ proved.

The changes in the acceptance of others are as Table 10. Examinee A, B, and G's acceptance of others rose, and examinees $\mathrm{C}$ and $\mathrm{E}$ decreased in Post-1. Because of the big rise (+4) of examinee $\mathrm{G}$, the average of the number improved compared to the Pre. In Post-2, the results of the examinee $\mathrm{B}$ and $\mathrm{G}$ improved, and examinees $\mathrm{C}, \mathrm{E}, \mathrm{F}, \mathrm{H}$, and I decreased. As a result, all the examinees' number resulted to be 4 . 
We analyzed the free descriptions of Post- 1 and Post-2. Table 11 shows the main result of open coding. At Post-1, the descriptions of role recognition are the most frequent. At Post-2, the descriptions about the changes in acceptance of others increased.

Open coding results are as Table 12. As the description for the changes in self-acceptance, there were many descriptions about the character of themselves for Post-1. As the description for the changes in acceptance of others, there were many comments about utilizing team members' strong points, the existence of the team members taking the role that the individuals are not recognizing, and taking communications with the team members for Post-2. As for the role recognition, there were many comments about the subjective actions for Post-1.

Table 9: The changes in self-acceptance.

\begin{tabular}{|c|c|c|c|c|c|}
\hline & Pre & Post-1 & $\begin{array}{c}\text { Pre vs } \\
\text { Post-1 }\end{array}$ & Post -2 & $\begin{array}{c}\text { Pre vs } \\
\text { Post-2 }\end{array}$ \\
\hline A & 4 & 4 & & 4 & \\
\hline B & 2 & 3 & +1 & 3 & +1 \\
\hline C & 4 & 4 & & 4 & \\
\hline D & 5 & 5 & & 5 & \\
\hline E & 4 & 4 & & 5 & +1 \\
\hline F & 2 & 4 & +2 & 2 & \\
\hline G & 4 & 4 & & 4 & +2 \\
\hline H & 1 & 2 & +1 & 3 & \\
\hline I & 5 & 5 & & 5 & \\
\hline J & 5 & 3 & -2 & 5 & \\
\hline K & 4 & 1 & -3 & 4 & \\
\hline Average & $\mathbf{3 . 6}$ & $\mathbf{3 . 5}$ & & $\mathbf{4 . 0}$ & \\
\hline
\end{tabular}

Table 10: The changes in the acceptance of others.

\begin{tabular}{|c|c|c|c|c|c|}
\hline & Pre & Post-1 & $\begin{array}{c}\text { Pre vs } \\
\text { Post-1 }\end{array}$ & Post -2 & $\begin{array}{c}\text { Pre vs } \\
\text { Post-2 }\end{array}$ \\
\hline A & 4 & 5 & +1 & 4 & \\
\hline B & 2 & 4 & +2 & 4 & +2 \\
\hline C & 5 & 4 & -1 & 4 & -1 \\
\hline D & 4 & 4 & & 4 & -1 \\
\hline E & 5 & 4 & -1 & 4 & -1 \\
\hline F & 5 & 5 & & 4 & +3 \\
\hline G & 1 & 5 & +4 & 4 & -1 \\
\hline H & 5 & 5 & & 4 & -1 \\
\hline I & 5 & 5 & & 4 & \\
\hline J & 4 & 4 & & 4 & 4 \\
\hline K & 4 & 4 & & 4.0 & \\
\hline Average & $\mathbf{4 . 0}$ & $\mathbf{4 . 5}$ & & $\mathbf{4 . 0}$ & \\
\hline
\end{tabular}


Table 11: The main results of open coding.

\begin{tabular}{|l|r|r|r|r|}
\hline \multirow{2}{*}{} & \multicolumn{2}{|c|}{ Post-1 } & \multicolumn{2}{c|}{ Post-2 } \\
\cline { 2 - 5 } & number & \multicolumn{1}{c|}{$\%$} & number & \multicolumn{1}{c|}{$\%$} \\
\hline The changes in self-acceptance & 12 & 26 & 7 & 19 \\
\hline The changes in acceptance of others & 11 & 23 & 14 & 39 \\
\hline Role recognition & 21 & 45 & 11 & 33 \\
\hline Other comments & 3 & 6 & 3 & 8 \\
\hline TOTAL & $\mathbf{4 7}$ & $\mathbf{1 0 0}$ & $\mathbf{3 6}$ & $\mathbf{1 0 0}$ \\
\hline
\end{tabular}

Table 12: Open Coding results (the ratio of the number of people).

\begin{tabular}{|c|c|c|c|}
\hline & Open Coding Results & Post-1 & Post-2 \\
\hline \multirow{4}{*}{$\begin{array}{l}\text { The changes in self- } \\
\text { acceptance }\end{array}$} & Noticed one's character to utilize one's strengths & $72.7 \%$ & $27.3 \%$ \\
\hline & $\begin{array}{l}\text { Be aware of the possibility of conflict with the oppo- } \\
\text { site type members }\end{array}$ & $18.2 \%$ & $9.1 \%$ \\
\hline & Try to explain logically & $9.1 \%$ & $9.1 \%$ \\
\hline & $\begin{array}{l}\text { Act naturally by not putting too much pressure on } \\
\text { oneself }\end{array}$ & $9.1 \%$ & $0.0 \%$ \\
\hline \multirow{6}{*}{$\begin{array}{l}\text { The changes in ac- } \\
\text { ceptance of others }\end{array}$} & Be conscious of the strengths of each other & $27.3 \%$ & $27.3 \%$ \\
\hline & Show concern to other members & $27.3 \%$ & $0.0 \%$ \\
\hline & $\begin{array}{l}\text { Observe other team members from different view- } \\
\text { points }\end{array}$ & $18.2 \%$ & $18.2 \%$ \\
\hline & $\begin{array}{l}\text { Listen to other members to communicate further with } \\
\text { other members }\end{array}$ & $18.2 \%$ & $18.2 \%$ \\
\hline & Utilize other members' strengths & $0.0 \%$ & $27.3 \%$ \\
\hline & $\begin{array}{l}\text { Recognize the existence of the team members taking } \\
\text { the role that the individuals have not recognized }\end{array}$ & $81.8 \%$ & $36.4 \%$ \\
\hline \multirow{5}{*}{ Role recognition } & $\begin{array}{l}\text { Take actions subjectively by observing the whole } \\
\text { team }\end{array}$ & $81.8 \%$ & $36.4 \%$ \\
\hline & Take actions subjectively for the team & $45.5 \%$ & $36.4 \%$ \\
\hline & Be conscious of one's standing position & $18.2 \%$ & $9.1 \%$ \\
\hline & $\begin{array}{l}\text { Find out the difference between the role recognition } \\
\text { of oneself and the whole team }\end{array}$ & $9.1 \%$ & $0.0 \%$ \\
\hline & Be conscious of the team balance & $0.0 \%$ & $18.2 \%$ \\
\hline
\end{tabular}

We describe the result of the interview to five examinees in Table 8 according to the changes occurred to them on self-acceptance and acceptance of others by the advice sheet. We describe the detailed comments we acquired from the examinees below. 
(1) Increase of self-acceptance

- I did not notice that I have strengths in divergent thinking. I could reflect on my strengths by receiving the advice sheet. (examinee $\mathrm{B}$ )

- The advice to myself gave me a trigger to change action inside the team. I have not recognized the 2-axis, "divergent and convergent" and "emotional and logical". I found out that we can consciously utilize the strengths of the team members, whether the team is in a divergent or convergent situation. I have known that there is a divergent and a convergent phase, however, I haven't had a recognition that we can share roles. (examinee B)

- The advice relieves my anxiety by giving me a whole image of the team and the idea of my position inside the team. I become anxious when I need to consider how to contribute to the team. The advice sheet makes me feel that there are spaces I can utilize my strengths. (examinee B)

- I make efforts to diverge the ideas because it is difficult for me to converge the discussion. I did not understand my strong points when the team was organized. The strengths I can utilize are different from the points I utilize in business situations. (examinee E)

- I have lost track of myself now. I used to recognize my strong point as facilitation and harmonization belonging to the "logical x convergent" type. However, I noticed that "logical $\mathrm{x}$ convergent" is not effective for my team. It is difficult to facilitate the team to a consensus when the ideas have emotionally diverged. There are diverse ways of decision making. (examinee $\mathrm{H}$ )

- Our team's problem is consensus building. We have a good idea, but the problem is the process to make one's idea to everyone's idea. (examinee $\mathrm{H}$ )

- I accept the advice that I have a "sense of balance". But the problem is that my team does not need it now. My power to converge is not strong enough. The team needs the convergent thinking that can convince everyone. I am looking for a way to strengthen my convergent thinking. (examinee $\mathrm{H}$ )

(2) Decrease of acceptance of others

- I consciously recognize the role-sharing inside the team after receiving the advice sheet. It verbalizes and visualizes the perspective of other team members which I have not noticed. (examinee $\mathrm{C})$

- I used to think that I understand other members well. However, through the advice sheet, I noticed that there are aspects I have not noticed. My viewpoint is still too narrow. (examinee C)

- I held a dialogue session according to the advice telling me that it is effective to unleash the team members' abilities by enhancing communication. I became more interested in team members. Then, I found new aspects of the team members who I used to have a stereotype. (examinee $\mathrm{C}$ ) 
- I've consciously valued the acceptance of others. I try to find an important role inside the team. Actually, I might have been just trying to express myself, instead of accepting others. (examinee $\mathrm{C}$ )

- I was discussing with people outside the team that we should understand individual's and other members' roles when working in teams. I received the advice sheet just after our team shared the purpose and goal to join this project. It verbalized our discussion and I felt like checking the answers. (examinee E)

(3) Increase of acceptance of others

- I decided to rely on other members who have different strong points from myself. Someone else may work on things I am not good at. (examinee B)

- The input that each member has a different position in the team was a trigger for me to be aware of the timing to diverge and converge during team activity. I recognized the timing as a kind of pattern. (examinee $G$ )

- I became careful when communicating with "Emotional x Convergent" type members by understanding that I tend to conflict with them. I realized which kind of persons I am compatible and incompatible with. (examinee $\mathrm{G}$ )

- Since I am not interested in people, I haven't been conscious of other team members. I didn't want to expect too much on others, so I was not interested in people. Also, I believe it is difficult to change people. This is the reason for my motto to change myself, instead of changing others, according to the situation. (examinee G)

- By acquiring the patterns in team activities, I can plan a strategy based on the assumption that it is difficult to change others. Now, I listen to emotional type members more, who I used to ignore. I am trying to understand other people. (examinee G)

- I have started to explore my strengths since I received the advice sheet. I realized that it is necessary to make decisions. I used to act on my impulse. I am making efforts to understand and get over my weak points. (examinee $\mathrm{G}$ )

We received comments below on the advice sheet (2-axis and written advice) and the timing to send the sheet through the interview.

(1) Effect of 2-axis

- 2-axis is more understandable than the usual personality test. When there is too much axis, it is difficult to understand, but 2-axis is very simple. (examinee B)

- For example, 16 types are too much to understand. On the other hand, 2-axis is simple and easy to understand. I was convinced by the result too. (examinee G)

(2) Effect of the advice

- I became satisfied after understanding my type at first. At next, since I tend to change my role according to the team balance, team advice became more useful. (examinee $\mathrm{C}$ ) 
- The overview advice was very interesting. 3 points were especially inspiring. (1) there are taken roles that you are not aware of, (2) hint to the communication with members who emotionally converge ideas, (3) "please enjoy this team activity!". Especially, (3) helped me to be more active to provide my idea to the team. I was feeling myself not contributing enough to the team and feeling too much responsibility to conclude a team (examinee $\mathrm{H}$ ).

(3) The timing to send the advice sheet

- The advice sheet is useful to consider how to engage in the project. It may become a guide to recognize the position in the team at the beginning phase of the team. I feel lost and not sure how to engage in the team when the relationship in the team is not built enough. (examinee B)

- The advice sheet may be useful to receive when the team is organized. I want to know each member's role recognition at first. The sheet could be sent at the beginning, mid-term, and final phases of the project to observe the changes. (examinee $\mathrm{C}$ )

\section{Discussion}

(1) The changes in self-acceptance and acceptance of others

According to the comparison of the pre and post-survey, we can indicate that the proposed method improves the examinees who have low self-acceptance and acceptance of others, who are the target of this study, as Table 13 and Table 14.

Table 13: The changes in self-acceptance (Low examinees).

\begin{tabular}{|c|c|c|c|c|c|}
\hline & Pre & Post-1 & $\begin{array}{c}\text { Pre vs } \\
\text { Post-1 }\end{array}$ & Post -2 & $\begin{array}{c}\text { Pre vs } \\
\text { Post-2 }\end{array}$ \\
\hline B & 2 & 3 & +1 & 3 & +1 \\
\hline F & 2 & 4 & +2 & 2 & \\
\hline H & 1 & 2 & +1 & 3 & +1 \\
\hline
\end{tabular}

Table 14: The changes in the acceptance of others (Low examinees).

\begin{tabular}{|c|c|c|c|c|c|}
\hline & Pre & Post-1 & $\begin{array}{c}\text { Pre vs } \\
\text { Post-1 }\end{array}$ & Post -2 & $\begin{array}{c}\text { Pre vs } \\
\text { Post-2 }\end{array}$ \\
\hline B & 2 & 4 & +2 & 4 & +2 \\
\hline G & 1 & 5 & +4 & 4 & +3 \\
\hline
\end{tabular}

Comparing the result of Post- 1 and Post-2, seemingly the level of self-acceptance decreased in Post- 1 and the level of acceptance of others decreased in Post- 2 . However, we consider that that is because they realized their over-confidence to the understanding of themselves and other members from the objective view from the advice writer. It led to self-reflection and the observation of other members.

\section{(2) Open Coding Results}

We state using open coding results for the changes in self-acceptance and acceptance of others, and role recognition. According to the open coding result, the recognition process starts with the 
role recognition of themselves (self-acceptance), which is followed by the acceptance of others. This process is suggested by the interview to examinee $\mathrm{C}$; " I became satisfied after understanding my type at first. At next, since I tend to change my role according to the team balance, team advice became more useful. "

This process is also similar to the process in organizations, which starts from understanding the situation and leads to share the common recognition in the organization. The process results in the decision making of executions [1]. For the case of teams, the process starts from the understanding of the character of oneself and leads to share the role recognition in the team. In this case, the process results in the changes in communication with other members

Detail discussions to each comment are as follows.

First, we state the changes in self-acceptance. "Noticed one's character to utilize one's strengths" means that the advice sheet motivated to understand individuals' characters and strengths at a higher level. "Be aware of the possibility of conflict with the opposite type members" refers to the fact that the advice sheet enhanced the self-understanding by noticing that it is easier to conflict with the opposite type members. "Try to explain logically" refers to the fact that the individual decided what to be conscious of by understanding one's character. "Act naturally by not putting too much pressure on oneself" means that the individual accepted one's personality and decided to act according to it. We consider that the method suggests the effectiveness of changing self-acceptance.

Second, we state the changes in the acceptance of others. "Be conscious of strengths of each other" refers to the fact that the individuals' conscious to utilize other members' strengths, not just themselves. "Show concern to other members" means the individuals' conscious to take care of other members are rising. "Observe other team members from different viewpoints" refers to the fact that the individuals acquired the new viewpoint through the advice sheet and the motivation to discover new aspects of other members. "Listen to other members to communicate further with other members" means that the individuals are motivated to communicate with others as the first step of acceptance of others. "Utilize other members' strengths" means that the individuals are motivated to detect other members' strong points. "Recognize the existence of the team members taking the role that the individuals have not recognized" refers to the fact that the individuals recognized that there are strengths of other members that they are not aware of, which leads to conscious actions. We consider that the method suggests the effectiveness to change the acceptance of others.

Finally, we state the role recognition. "Take actions subjectively by observing the whole team" and "Take actions subjectively for the team" means that the individuals are motivated to take actions based on their role recognition through the attention of the whole team. "Be conscious of one's standing position" refers to the fact that the individuals' understanding of their position in the team is enhanced by noticing the other members' role recognition. "Find out the difference between the role recognition of oneself and the whole team" means that the advice sheet revealed the differences in role recognition in the team. "Be conscious of the team balance" refers to the fact that the advice sheet enhanced the conscious of the team's role balance. We consider that the method suggests the effectiveness of role recognition. 
(3) Interview Results

We attempt to indicate the effects of the advice sheet to increase self-acceptance and acceptance of others and decrease the acceptance of others through the analysis result of the interviews to the five examinees, according to the changes that occurred to them by the proposed method. Figure 5 shows the relation between the effect of the proposed method and the comments acquired from the interview. "Increase of self-acceptance" occurs by giving individuals a recognition of their strengths or roles they can take in the team, which leads to the motivation to change action during the team activity. "Decrease of acceptance of others" sounds seemingly negative, however, it affects the individuals to notice new aspects of the team members by mitigating the overestimation that they understand the team members' characters enough. "Increase of acceptance of others" occurs by reflecting the strengths of the team members, which leads to the mindset to utilize the strengths of each team member.

We confirmed from the interview results that the simple and understandable 2-axis, the advice to individuals and the team, and the advice which give excitement and special feelings to the individuals enhance the effect of the advice sheet. In addition, we acquired the suggestion to send the advice sheet just after the team has been organized. It leads to enhance the performance of the teams by utilizing the strengths of the team members at the earlier timing through role recognition.

\begin{tabular}{|c|c|c|}
\hline \multicolumn{2}{|c|}{ Effect of the advice sheet } & Comments from the interview \\
\hline \multirow{2}{*}{$\begin{array}{l}\text { Increase of } \\
\text { self- } \\
\text { acceptance }\end{array}$} & $\begin{array}{l}\text { Recognize } \\
\text { individual's } \\
\text { strengths and role in } \\
\text { the team }\end{array}$ & $\begin{array}{l}\text {-I did not notice that I have strengths in divergent thinking. I could reflect on my strengths by } \\
\text { receiving the advice sheet. (B) } \\
\text {-I make efforts to diverge the ideas because it is difficult for me to converge the discussion.(E) } \\
\text {-I accept the advice that I have "sense of balance". But the problem is that my team does not } \\
\text { need it now. (H) }\end{array}$ \\
\hline & $\begin{array}{l}\text { Change behavior } \\
\text { during team activity }\end{array}$ & $\begin{array}{l}\text { - The advice to myself gave me a trigger to change action inside the team. (B) } \\
\text { - The team needs the convergent thinking that can convince everyone. I am looking for the way } \\
\text { to strengthen my convergent thinking. }(\mathrm{H})\end{array}$ \\
\hline $\begin{array}{l}\text { Decrease of } \\
\text { acceptance: } \\
\text { of others }\end{array}$ & $\begin{array}{l}\text { Be aware of team } \\
\text { members' new } \\
\text { aspect }\end{array}$ & $\begin{array}{l}\text {-I used to think that I understand other members well. However, through the advice sheet, I } \\
\text { noticed that there are aspects I have not noticed. (C) } \\
\text {-I received the advice sheet just after our team shared the purpose and goal to join this project. } \\
\text { It verbalized our discussion and I felt like checking the answers. (E) }\end{array}$ \\
\hline $\begin{array}{l}\text { Increase of } \\
\text { acceptance } \\
\text { of others }\end{array}$ & $\begin{array}{l}\text { Utilize team } \\
\text { members'strengths }\end{array}$ & $\begin{array}{l}\text { - I decided to rely on other members who have different strong points from myself. Someone } \\
\text { else may work on things I am not good at. (B) } \\
\text { - By acquiring the patterns in team activities, I can plan a strategy based on the assumption that } \\
\text { it is difficult to change others. Now, I listen to emotional type members, who I used to ignore. I } \\
\text { am trying to understand other people. (G) }\end{array}$ \\
\hline
\end{tabular}

Figure 5: The Effect of the advice sheet indicated by the interview results.

\section{Limitation of this Study}

As mentioned in the explanation of the proposed method, we can only identify the multi-roller by the variation of the role they take during the research period. 
In this study, we ask the role they are taking consciously. Therefore, this study has not clarified the role they take unconsciously. By using the measures of previous studies, we can measure the examinees' creative thinking from their behaviors.

We used the changes in self-acceptance and acceptance of others as an evaluation of the proposed method. There should be other elements that are affected by the method, for instance, psychological safety.

In this study, we focused on subjective changes occurred to the examinees through the self-reported changes to evaluate the effect of the advice sheet. However, it is possible to objectively identify the changes that occurred to each individual by conducting mutual evaluation among team members.

\section{Conclusions}

According to the result of the comparisons of pre and post surveys, free descriptions to the postsurvey, and interview analysis, we clarified that the proposed method improved the acceptance level of the examinees that have low self-acceptance or acceptance of others at the pre-survey, who are the target of this study. In addition, we indicate that the proposed method induced the behavior changes to the examinees that have high self-acceptance or acceptance of others.

As the future research topic, we would send the advice sheet immediately after the team is organized. That is because, it may lead to enhance team performance by utilizing the strengths of the team members at the earlier timing through role recognition, according to the interview results. Also, future research topic needs to identify the changes and effectiveness by sending the advice for a longer period. Future research topic needs further discussions to improve the contents of advice as well, in order to enhance the team performance in a moreover effective way. For instance, we can test the positive effect on the team performance by not sending the concrete advice but showing the role balances in 2-axis. Also, when the whole team answers the pre and postsurvey, we can test the effects by identifying the team members. This time we chose to conduct an anonymous survey to make the examinees feel safe to answer. However, it might be more effective to the team performance by identifying each person's role recognition in the team.

\section{Acknowledgment}

Mayu Akaki, the first author of this research, is supported research activities by Tsukuru to Ugoku Design Co., Ltd. (http://www.tu-design.jp/).

\section{References}

[1] N. Kobayashi, A. Nakamoto, M. Kawase, F. Sussan, S. Shirasaka, "What Model(s) of Assurance Cases Will Increase the Feasibility of Accomplishing Both Vision and Strategy?", Review of Integrative Business and Economics Research, Vol. 7, No.2, 2017, pp. 1-17.

[2] Hiroe Kawagichi, "The Study on Self-Acceptance \& Acceptance of Others with Accentuation on Measures of Acceptance", Jap. J. of Educ. Psychol, VOL. XX, No.3, 1972, pp.34-42 
[3] KASUGA Yumi. "A Study on Self-acceptance and its Measurement", Journal of The Human Development Research, Minamikyushu University 2015, Vol.5, pp.19-25

[4] R. Meredith Belbin, "Management Teams: Why They Succeed or Fail”, Heinemann Professional Publishing, 1981

[5] Ken'ichiro Tanaka, "Social psychological considerations on the metamorphosis of self-concepts in the leader development process", Rikkyo Psychological Research, 2013, Vol.55, pp.79-88

[6] Tomohiro Takanashi, "Chi-Management”, HAKUTO-SHOBO publishing company, 2009, pp.119 Figure7-5

[7] Ricardo Ortega-Sanchez, M.D., Carmelo Jimenez-Mena, M.D., Rodrigo Cordoba-Garcia, M.D., Joaquin Munoz-Lopez, M.D., Maria Luisa Garcia-Machado, M.D., and Jordi VilasecaCanals, M.D., "The effect of office-based physician's advice on adolescent exercise behavior", Preventive Medicine 38, 2004, pp.219-226

[8] Angela Hung and Joanne Yoong, "Asking For Help: Survey And Experimental Evidence On Financial Advice And Behavior Change”, RAND Working Paper Series WR-714-1, 2010, pp.1-47

[9] Saito, N, "The Development of the Attitude Scale of Creativity in Mathematics Education For Elementary School (grade 6) and Junior High School (grade 1-3) Students-", 1999, Japan Academic Society of Mathematics Education, Vol.5, pp.35-46

[10] Guilford J.P. \& Hoepfner, R., The analysis of intelligence, 1971, McGraw-Hill

[11] Naito, M., Suzuki, K., and Sakamoto, A, "Development of Rational and Intuitive Information-Processing Style Inventory”, 2004, The Japanese Journal of Personality, Vol 13, No 1, pp 67-78

[12] Pacini, R., and Epstein, S. "The relation of rational and experiential information processing styles to personality, basic beliefs, and the ratio-bias phenomenon", 1999, Journal of Personality and Social Psychology, 76, pp 972-987

[13] Design Council, "The Design Process: What is the Double Diamond?",2015, URL: https://www.designcouncil.org.uk/news-opinion/design-process-what-double-diamond (Last accessed on 26th March 2019)

[14] Barbara Minto, "The Pyramid Principle: Logic in Writing and Thinking", Financial Times Prentice Hall, 2008

[15] Eugene B. Zechmeister, James E. Johnson, "Critical Thinking: A Functional Approach", Brooks/Cole Pub Co, 1991

[16] John D. Mayer, "The Intelligence of Emotional Intelligence", Intelligence 17, 1993, pp.433442 
[17] N.Kobayashi, A.Nakamoto, M.Kawase, S.Shirasaka: Comparison of Two Quantitative Evaluation Methods for Assurance Cases, International Journal of Japan Association for Management Systems, Vol. 8 No.1, 2016, pp.27-34

[18] N. Golafshani: Understanding Reliability and Validity in Qualitative Research, The Qualitative Report Volume 8 Number 4 December 2003, 2003, pp.597-607 